\title{
Analyzing the Visuals and the Message Sent in the INAI Spot in Mexico
}

\author{
Gustavo Sebastián Rodas Hernández \\ University of Guanajuato, MEXICO \\ Division of Social Sciences and Humanities
}

Received: 1 June 2020 • Accepted: 21 August 2020 - Published Online: 4 October 2020

\begin{abstract}
The use of media has been used for several purposes, such as entertainment, leisure activity, or as mean to communicate. Currently, federal institutions have employed media with the purpose of being in touch with people. In this case, through radio and video spots the INAI tries to send a message that comforts and reliefs the population in Mexico. In order to discuss such message, I analyze the discourse in the radio spot and the pictures used in the video. The former is examined by the systemic functional linguistics provided by Halliday (1978) and the latter with the Machin's (2010) visual semiotic framework. The findings portray a discourse that pretends solving the problematic situation the country already faces. However, there is not a solid conclusion only a pretentious scape of the responsibility of other federal institutions.
\end{abstract}

Keywords: discourse analysis, media, INAI, messages, SFL.

\section{Introduction}

In Mexico, social media has been broadcasting several spots in radio and TV through the years to fulfill what people demands from the government institutions. This paper aims to scrutinize the message sent in the INAI (Instituto Nacional de Transparencia, Acceso a la Información y Protección de Datos Personales) video. The video is presented to the Mexican audience in two different formats: the first as a spot in the radio and the second as a video in TV and as an advertisement in the TV and internet. The message sent by the INAI attempts to solve possible questions that people may have regarding the federal budget and how is spent. To approach the analysis, I will mainly use the Systemic Functional Linguistics (SFL) proposed by Halliday (1985) as referent in the analysis of the discourse. The video and images on it will be approached through the Machin's (2010) visual semiotic framework. The paper will present a brief introduction of the context of Mexico and what the INAI represents to clarify what is the purpose of the message. Then, the methodology employed in the analysis will be discussed and followed by a discussion of the findings. Finally, the paper will close with a brief conclusion.

\subsection{Political discourse in Mexico}

Mexico has experienced challenging scenarios during the years due to the sociopolitical conflicts that emerged from the government. In this case, the main stakeholders are the Mexican people. To understand this claim, it is relevant to explore how people is approached by

(C) Authors. Terms and conditions of Creative Commons Attribution 4.0 International (CC BY 4.0) apply. Correspondence: Gustavo Sebastián Rodas Hernández, University of Guanajuato, Division of Social Sciences and Humanities, Guanajuato, MEXICO. E-mail: gsrodher@outlook.com. 
the political parties. According to the statistics taken from the Consejo Nacional de Evaluación de la Política de Desarrollo Social (CONEVAL) in 2018, there exists 27.4 million of people who are not considered as low-social income nor vulnerable. This represents the $21.9 \%$ of the total population in the country. In a broadened perspective, 52.4 millions of people live in poverty, 9.3 millions more live under extreme poverty conditions, 8.6 millions are vulnerable because of their incomes, and 36.7 million are people who the government considered them as vulnerable because of the social lack.

Furthermore, in 2019 De Las Heras Demotecnia conducted a survey collecting data in regard to the main worries of Mexican people. The results highlighted that $34 \%$ of the people interviewed were concerned with the health system, $26 \%$ stated that security played an important role, and only $12 \%$ said that economy area needs to be addressed urgently, a fewer percentage mentioned that education has been neglected. Regarding the last point, the INEGI (2015) pointed out that the average educational level in Mexico is 9.1 academic grades. This means that the Mexican children instead spending an average of 12 academic grades enrolled in the educational system, (3 years in kindergarten, 6 years in primary, and 3 years in secondary school), most of them have only study 9.1 years of literacy.

This situation makes the construction of a thematic discourse for the government. Therefore, the federal and state politicians attempt to establish a link or bound between the Mexican people with the development of social programs, characters, modifications in laws, discourses that try to become in promises only to re-vindicate its composition as a keystone to reach to the Mexican people. The combination of all these perceptions coming from an unsatisfied society was an opportunity for the new President and its cabinet to demonstrate a change. Torcal (2003) relates this disenchantment with old Mexican mandatories due to the democracy consolidation they had at the time when they rule.

Otero (2018) remarked that the current Mexican President Andres Manuel Lopez Obrador (AMLO) self-proclaimed to his mandate the Fourth Transformation (4T). The $4 \mathrm{~T}$ pretends to solve and overcome some of the difficulties from previous years and decades. However, Otero (2018) states that to achieve such challenges, the government will require to do an extensive work to fulfill all the objectives presented before its official selection. The $4 \mathrm{~T}$ tries to eradicate two main problems: (1) the corruption, and (2) impunity. To manage them, several proposes arose. For example: the austerity project that influenced diverse institution all around the country with the purpose of diminish the financial investment, and the improvement of certain institutes, as in the case of the Instituto Nacional de Transparencia, Acceso a la Información y Protección de Datos (INAI). The latter will be explained in detailed in the following section.

\subsection{What is the INAI and what does it represent?}

Politicians have tried to depict themselves as people who care and consider the willing of society. To accomplish this goal, different sexennial periods have offered and constructed organizations that address the problems that society lives with. According to the CONEVAL (2018) between 2008 and 2016 there had been more than 1000 social programs. Some of these programs did not continue over the time, but some of them are still valid, such as: Aportaciones a la Segurida Social (APPS), Secretaria de Hacienda y Crédito Público (SHCP), Consejo Nacional de Ciencia y Tecnología (CONACYT), Instituto Mexicano del Seguro Social (IMSS), only to mention some. However, even when these programs support and assist certain sectors of society, incongruences seem to exist because people do not perceive their contributions as necessary. To provide information about the multiple programs in Mexico, another institution emerged as a way to bridge this gap, the IFAI/INAI. 
It is relevant to mention that the INAI was previously named as IFAI (Instituto Federal de Acceso a la Información y Protección de Datos). According to the official webpage of the Mexican Government, the IFAI was founded in 2002 and worked for 12 years and its main objectives were:

The fundamental objectives of this body are: to promote and disseminate the exercise of the right of access to information, resolve the refusal of requests for access to information and protect personal data in possession of the agencies and entities of the Federal Public Administration. (Machinelly, 2011: 1)

The objectives from the IFAI were similar to the INAI's. However, the reason of having this transition between these two programs was the publication of the Ley General de Transparencia released in 2014. Based on the information published in the official webpage of the Mexican Government, the INAI is described as:

The Autonomous Public Body in charge of facilitating and guaranteeing people's access to public information and access to and protection of personal data, promoting a culture of transparency in public management and government accountability to society. (Secretaria de Función Pública, 2020: 1)

Based on the above, the IFAI presented similar purposes as the INAI, but with minor differences. Its mission, vision, and objectives were the principal modifications this institute showed. The INAI created and approved more than 50 strategic programs that are used to facilitate its new legal functions (INAI, 2017). Thus, the INAI presented a solid beginning beneath society by stating its main purpose, which is: to permit people have access to the information and how the money taken from the taxes is invested.

Finally, the INAI attempts to represent and provide clear paths regarding information. Its creation and improvement came as a necessity from the government to be accountable on how the investment of taxes is followed, if the hospitals have enough medicine for the people's treatment or to know if politicians are working against the insecurity. The INAI broadcasted a spot in radio, TV, and on the Internet to establish bonds between the government and people. However, the INAI's message is more influential through the media because if the same discourse were depicted in written ways or orally, it would not be as efficient as in the TV or Internet. This is the potential media has when sending messages and will be approached in the follow theme.

\subsection{The influence of social media in Mexican society}

Through history, Mexico has moved and forward-thinking in term related to technology, science, education, and social media. However, the advances cannot be compared with more developed countries. For example, Hopf (2016) mentions that "Mexico, despite being a developing country, uses social media at a higher rate than countries with greater Internet penetration" (p. 45). This means that even when the country is still technologically evolving, Mexican people spend a considerable amount of time in social media compared to other countries. According to We are Social Singapore (2016) presented data that listed Mexico as one of three more eager countries concerned with the use of Internet in Latin America. Thus, the role of social media started to become more relevant and popular over the years not only for the citizens, but for the government as well. Based on Hopf's (2016) words:

Mexico's government officials have also recognized the power of social media. $@$ PresidenciaMex is "the most active of all world leaders' accounts with an average of 68 tweets per day," per Twinplomacy data. Likewise, the same report cited @EPN, President Enrique Peña Nieto's account, as "the most followed Latin American leader and the ninth most followed worldwide.” Mexico's president uses his Twitter account to promote official initiatives such as \#PactoporMexico, \#WEF (Word Economic Forum) or energy reform, \#ReformaEnergetica. (p. 32) 
Based on the above quote, it is evident that the Mexican government has an active role in regard to social media. The use of hashtags in Twitter works as an attempt to foster initiatives that link the political parties and the rest of people who lives in Mexico. Moreover, the large number of followers the ex-president Enrique Pena Nieto had, it demonstrates the fame and impact social media depicts in society. The transition between political purposes and other type of announcements in the media are described by McClenehgan and Ragland (2002). The authors suggest that to enhance the value in communication regarding democracy, public services and community, broadcasting media should not be restricted to commercial ads or announces.

Following these lines, Parkinson (2002) claimed that the use of media can be misunderstood and negatively affect to those who listen the message. For example, he says that the message from the politicians' debates are commonly confused in the media. The participants focus more on the opinions rather than debating, per se. The little attention given to social issues or institutions, and the irrelevant ideas given by them, it shows the power and importance of the social media. In this scenario, Parkinson (2002) analyzed the lack or plethora of ethics that media can depict on the real intentions from the message sent. Therefore, several political parties have realized the relevance for increasing the number of people who follow them through social media and how they can receive their messages in such platforms.

The outstanding upsurge of the use of new means has shaped the way people obtain information. Radio and TV are still sources used by people to be informed regarding the situation in Mexico, but social media has played a greater role. An example of this is given by Garcia-Murillo (2010) who states that the impact of Facebook or YouTube has when corruption is exposed in social networks. He also suggests that those scenarios can make politicians to be aware on how the public eye perceived them. In this case, Ramírez-Placencia (2015) mentions that:

States and organizations have established imperative actions to decrease corruption through ICT like creating virtual portals for showing information about public expenses or electronic sites for denouncing bribery and nepotism acts. But along the time, these actions are kind of limited, because usually people do not trust government authorities and they do not consult frequently this spaces. (p. 38)

In the previous quote, it is inferred that the government has tried to consolidate way to accomplish a sort of acceptance from the Mexican people. An example of this, is the INAI. The institution has sent messages in more updated ways. For instance, in the YouTube platform there is an advertisement when people wait for watching a video. In a superficial viewpoint, the INAI discourse can be interpreted as a proper option for the new government to leave the acts of previous sexennial periods. Nonetheless, scrutinizing the message under a more critical scope can shed light on a different message, which will be presented in further sections.

\section{Methodology}

Analyzing texts either in written or spoken means requires a degree of complexity. Whether the process is not cautiously developed, the level of credibility could be questioned by the audience. Therefore, the text in the INAI spot will be scrutinized using Halliday's (1985) SFL while the visuals will be examined through the Machin's (2010) framework to highlight the relevant elements implicitly shown. To provide an objective construction of the analysis, the following section will briefly describe the main elements in Critical Discourse Analysis (CDA).

\subsection{Critical Discourse Analysis (CDA)}

Having critical perspectives regarding the analysis of areas such as semiotics, pragmatics, psycho, and sociolinguistics started to become a trend since the last three decades. At 
the time, a prestigious group of scholars (Teun van Dijk, Norman, Fairclough, Gunther Kress, Theo van Leeuwen \& Ruth Wodak) discussed theories regarding the discourse analysis from a critical approach. As part of a paradigm, CDA distinguishes among other due to a series of particular characteristics. Wodak and Meyer (2008) mentioned that the deconstruction of pre-established believes, the self-reflection in research, and the language and power relation are the basis in CDA. Over the years, this paradigm began to be used as a way to highlight circumstances where the context is a crucial part of the problem to be approached. According to Wodak (2001) CDA "aims to investigate critically social inequality as it is expressed, signaled, constituted, legitimized, and on by language use (or discourse)" (p. 2). Carrying out this type of analysis has permitted to perceive and comprehend in different ways the discourses of diverse fields, such as: the academic institutions, politics, gender, and media discourse. Wodak (2001) mentions that is vital to consider that:

It is important to stress that CDA has never been and has never attempted to be or to provide one single or specific theory. Neither is one specific methodology characteristic of research in CDA. Quite the contrary, studies in CDA are multifarious, derived from quite different theoretical backgrounds, oriented towards different data and methodologies. (p. 5)

Taken into consideration this claim, CDA presents a multidimensional approach to analyze the same text or discourse, but under different conditions. By doing so, whoever that opt to work with it has the opportunity to scrutinize or criticize the discourses. Moreover, the diversity of the methods applied in this approach match with the conception given by van Dijk (1993) stating that CDA "shared perspective on doing linguistics, semiotic or discourse analysis" (p. 131). These points of view are intertwined with the diverse basis of the text within the discourse, the field to work with, and what it is attempted to explore under the scope.

In sum, CDA entails a variety of characteristics that permits its user to raise awareness of the context of the subject to be studied. The relationship between power and society, historical point of view of political moments, the uneven and unclear messages broadcasted through the gender and media, are elements discussed under such terms. Fairclough and Wodak (1997) mention that the context of the language is because is part of the social practice. However, CDA has expanded its branches and diversification in most recent years through the addition of new areas such as: multimodal discourse analysis, political discourse, dispositive analysis, sociocognitive approach, among others. Following this line, there exists a framework proposed by Halliday (1985), which will be further explained in detailed in the following section.

\subsection{Halliday's $S F L$}

As described in the previous section, there exists new branches concerned with the interpretation of the language, but there is one that distinguishes among others, the Halliday's (1985) SFL. According to Almurashi (2016), this approach has been utilized in diverse fields, such as: literature, linguistics, and applied linguistics. The use of SFL has taken a relevant part in global contexts and because of its principles, Wang (2010) mentions that is part of the core of CDA. The peculiarities of CDA and SFL lies on the analysis of the next aspects: (1) context, (2) semantics, (3) lexico-grammar, and (4) phonology.

Matthiessen and Halliday (as cited in Almurashi, 2016) described the first feature as "one of the central concerns, because it is integral to the overall process of making meaning. In fact, when language occurs in a context, it will relate to or is linked to a number of context" (p. 72). This element gives sense to the language because of their different subsystems folded in each. For example inside them, there are the context of culture and situation, and within it there are strands such as: the field, tenor, and mode. Based on Haratyan (2011), and Matthiessen and Halliday's 
(1997) words, the previous characteristics are used to create text and, thus, meaning to the language.

The union of these elements fits with the purpose of the paper, which is to scrutinize a spot broadcasted by a federal institution, the INAI. The kind of language will be processed under the four aspects shown above. By doing so, it is possible to analyze how the language was constructed and distributed through the spot. The importance of (co)constructing the term 'language' through these aspects lies on how it has evolved on its own meaning.

In sum, SFL is approached as a vital source in the analysis and interpretation in diverse fields of study. However, there are frameworks or approached that have an emphasis on different elements, as in the case of visuals or semiotics. The next section addresses and describes the Machin's (2010) framework that was a salient source in the analysis.

\subsection{Machin's framework}

Under all the different emerging branches from a CDA paradigm, the analysis of pictures is relevant to obtain more in-depth information regarding a distinctive subject. It may seem that every post or advertisement can be scrutinized, but the results can vary depending on the framework to be employed. Correspondingly this claim, Machin (2010) says that "we look for the kind of semiotics resource and patterns available for communication in the sounds, images and worlds popular music" (p. 3). By doing so, the field of semiotics and visuals can be approached under characteristics that can shed light on more particular details such as the colors and its communicative functions and dimensions within it. Regarding the matter of colors, Machin (2010) says when talking about colors, people evoke emotions and associated them to different moments of their life. These feelings can have the same communicative functions as language (Halliday, 1978). Kandinsky (1977) also declares that "color has two kinds of value. These are the direct value which is the effect it has on the viewer and the associative value" (p. 61). These conditions permit an analysis of six features that will be used in this paper, they are: (1) hue, (2) brightness, (3) saturation, (4) purity, (5) modulation, and (6) luminosity.

The above elements are essential to provide a better understanding of the video portrayed in the INAI's spot because as it has been said before, this paper will scrutinize the possible divergent messages coming from a federal institution. Thus, working with the Machin's (2010) framework is useful due to the images from the video shows several colors and little attention is given to the background cues and icons instead focusing on straight pictures with a political content. The discussion of the apparently hidden messages will be centered in the next section.

\section{Discussion of findings}

This part of the paper will discuss the finding concerned with the INAI video and will be presented in two sections. The first relates to the analysis of the discourse used in the video and how it pretends to bridge a problematic that is lived in the country through the use of verbs cautiously 'selected'. The second part is an analysis of the images presented in the video and how they impact on the audience's reception and perception of the message.

\subsection{Analysis of the discourse of the INAI spot}

This section is concerned with the analysis of the message of the video from the INAI. In order to scrutinize the text, SFL proposed by Halliday (1978) was employed. Such work was mainly focused on two frames: (1) context, and (2) semantics. The text to analyze comes from the 
INAI and belongs to the Mexican federal sector. The message aimed to reach to the whole country through the radio and as an advertisement in the media (TV and internet). Because of the lack of information of the spot, the INAI will be considered as the subject who wrote and directed the message. To understand the frame carried out, Halliday and Hasan (1989) define that:

(1) The field of discourse refers to what is happening, to the nature of the social action that is taking place.

(2)The tenor of discourse refers to who is taking part, to the nature of participants, their statuses and roles.

(3) The mode of discourse refers to what part the language is playing. (p. 12)

Having presented these three terms, the following Table depicts the analysis of the INAI spot from a situational context approached.

Table 1. Field, tenor, and mode frames

\begin{tabular}{|l|l|}
\hline Field & $\begin{array}{l}\text { Maintenance of institutional system of beliefs, political ideologies (4T), and two } \\
\text { social classes group (Mexican people and Mexican federal institutions). }\end{array}$ \\
\hline Tenor & $\begin{array}{l}\text { Authority (for example, the INAI is the institution holding authority, and specialist) } \\
\text { to the audience. Audience is perceived as unseen and unknown (like readership), but } \\
\text { there exists a relationship institutionalized through the problems (INAI to Mexican } \\
\text { people). }\end{array}$ \\
\hline Mode & $\begin{array}{l}\text { Through visuals, the message is written and told aloud. Public act (radio, TV, and } \\
\text { Internet). The text is persuasive with rational and ideal arguments. }\end{array}$ \\
\hline
\end{tabular}

Based on Table 1, the field is thus the maintenance of an institutionalized systems of belief applied to the Mexico current situation. The political field attempts to make contact with the people through the concept that there exists the INAI, which is a federal institution that enhance the clarification and resolution of doubts in the country. At the same time, this assumption seems to divide context in two parts. The first one is concerned with the people who is questioning what is happening. The second portrays the government as a 'savior' that establishes that under this sexennial term most questions are solved. This ideology is attached to the political speech from the $4 \mathrm{~T}$ in regard to "No (vamos a) ocultar nada, no (vamos a) ser tapadera de nadie".

The tenor is that of an authority to an audience. The INAI introduces itself in the message as an authority in different senses. For example, it holds authority above other federal institutions (i.e. hospitals, public security, and public works), and is an authority on politics. As an authority, the INAI gives for granted and assumes that several people in the country cope with problems and doubts regarding the different aspects of Mexico. It is in this scenario where the INAI tries to establish a relationship with the people. Although it does not know the diversity of public comprised in the audience, and cannot foresee who would listen or watch the message, there is still a relation imposed by Mexican culture. Over the years, political parties are supposed to be the responsible to look after the welfare of the country. Therefore, it is presumed that the government has the obligation to support and help all the Mexican people.

Finally, the mode is that of a text that was written and can be seen in the video and it is read aloud by a narrator. The message is broadcasted as a public act on the mass media in a mean of conversation. When talking, the people react and show their doubts about what the government is doing and the INAI appears as a mediator that foster them to keep asking and reaffirming the people's rights to ask. This is important because this institution tries to send its message with a rational and ideal discourse.

In order to provide a solid support to these claims, the use of semantics will be used. Even when the video has a short length, its main discourse is focused on two settings which are: the existential and ideational. The former is mentioned in the field frame above, and portrays its 
connection with the fact of having an institution in charge of the Mexican population's doubts. This is supported by the following verbs and phrases employed in the discourse: para eso están, tiene, deben. These verbs denote believes related to the ideal function of the government and the rational thinking concerned with questioning. Moreover, the verbs also establish a relationship between the problems that exist in the Mexican context and the way they seem to be unsolved.

The ideational term is mentioned in the tenor frame. The principal relation is presenting the INAI as an authority. The power given to this institution comes from the government and attempts to be a 'savior' for those who are scared or do not feel secure enough to ask about what is currently happen in Mexico. This is demonstrated through the use of verbs and phrases such as: preguntar, preguntales, pregunta a los ..., el INAI defiende tu derecho, el que pregunta, no se que equivoca. Thus, the role of the INAI suggest to encourage people (who may be considered as A) to ask the federal authorities (who may be considered as B) or in other words, sends A to B. However, what comes after will be discussed in the conclusions.

\subsection{Visual semiotic analysis of the videos}

Once the analysis of the message was approached, the visual part will be scrutinized using the Machin's (2010) framework that emphasizes six characteristics previously mentioned. In addition, images will be included to have a better understanding of the process, which will be carried out through the levels aforementioned.

\subsubsection{Hue}

Machin (2010) claims that hue "has meaning potential due to the association and symbolic associations of the color itself" (p. 67). He also mentions the use of this term to connect ideologies and concepts based on the context: for example, Itten (1974) and Gage (1993) say that there are colors that are associated to abstract concepts such as: purity, science, truth, angry. Under these concepts, it can be appreciated that few colors are used in the video. For example: pink and orange, which are employed to represent women in the spot, as shown in Image 1 and 2.
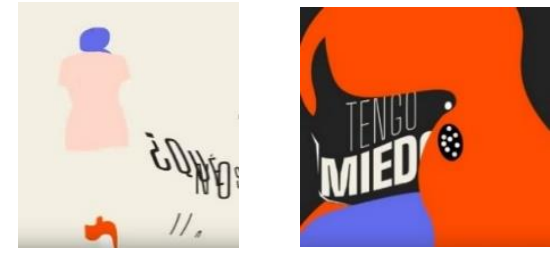

Image $1 \& 2$. Use of colors for women (Source: INAI)

What is more remarkable is the contrast presented when questions are made and answer. In this case when the video presents interrogative statements, the background color changes to black and white, which represents doubts and fears regarding situations lived in the country (See Image 3).

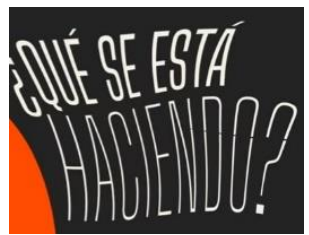

Image 3. Representation of dark background when using interrogative statements (Source: INAI) 
In order to solve the questions, the background changes on the opposite colors scale. The background turns from black to white, as an attempt to represent clarity and trustworthiness as it is referred in Image 4.

\section{PREGUNTA \\ a los encargados de seguridad QUE PARA ESO ESTÁN}

Image 4. Representation of light background when answering questions (Source: INAI)

The letters that were in clear colors change to blue trying to provide wisely solutions to what has been stated before.

\subsubsection{Brightness}

When analyzing pictures or videos, the role of brightness plays a relevant role. Machin (2010) suggests the potential of this frame "rests on the fundamental experiences we have with light and dark" (p. 62). It is not new the symbolic meaning that lies on these two aspects, but for long years it has been proved darkness is commonly associated with negative thoughts while light with positive ones (Whitehead \& Wright, 2004; Low \& Lawrence-Zuñiga, 2003). The INAI video displays two main tones, light and dark. According to the familiar association, the video depicts the questions in a way that can be perceived as negative. Evidence of this can be demonstrated in the black background that is used when interrogative statements are show as in the example of Image 3 and in the Image 5 .

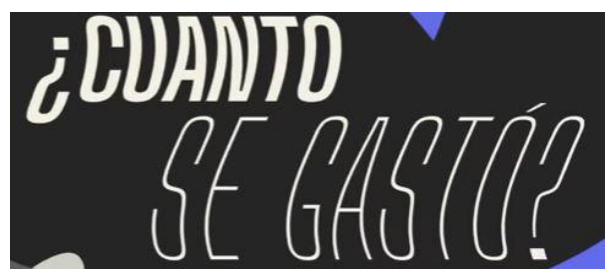

Image 5. Example of interrogative statement with a dark background (Source: INAI)

The questions concerned with problems in Mexico such as: the insecurity women lives with, the absence of medicine that hospitals face, and how the taxes are invested in public works. The interrogatives portrayed through the black background make an emphasis on problems, violence, negative perceptions, and disease in Mexico. However, the background changes into bright and white when the INAI attempts to answer those questions. Having a bright background reflects positive thoughts, a cure or simply a resolution for these aspects as in Image 4 and 6.

\section{PREGUNTA DEBEN SABER}

Image 6. Use of bright background when giving solutions (Source: INAI) 
In this case, the use of brightness aims to settle the interrogatives as part of a problematic and the INAI as the answers for them. Lakoff and Johnson (1980) refers the use of dark tonalities as ignorance or lies. While light tones refers to the use of reason and truth. Thus, the use of brightness in the video tries to frame the two sides of a coin. On the one side, ignorance, problems, and doubts are shown with a dark background. On the other hand, the solution of those prerogatives are solves with the use of a light background that evokes clarity.

\subsubsection{Saturation}

While hue and brightness have denoted a relationship between colors and perceptions, saturation is used to represent the emotional temperatures. Machin (2010) says that "a highly saturated color can mean a maximum intensify of feeling, whereas a pale color can mean toned down, neutralized or subdued" (p. 63). Thus, the more saturated the pictures are, the more adventurous or exuberant can be perceived while the lower degree of saturation is, the tendered and milder, the energy can mean. The video of the INAI shows a combination of high and low levels of saturation. On the one hand, the low tones in the video transpires the hectic situation lived in the country or at least the concerns that Mexican people have, as shown in Images 7 and 8.
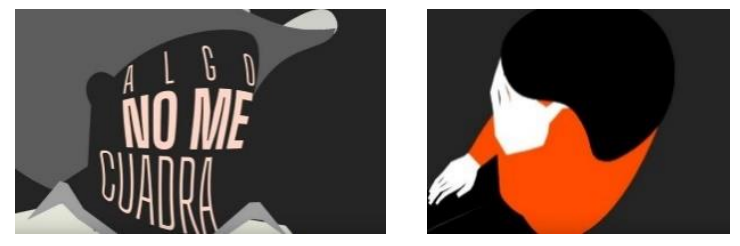

Images 7 \& 8. Examples of low tones regarding saturation (Source: INAI)

Following the same lines, the use of pale colors can be related to negative emotions or even a subdued perception such situations. On the other hand, high saturated palettes of colors reflect the intensity or necessity for solving the already mentioned problems. These process is done through the change of saturation depicted on the Images 4 and 6 previously. The kind of contrast regarding saturation is managed in order to pre-establish the regular situation lived in the country under a negative frame and the inclusion of the INAI as a solution or even as the institution that solves the questions the country may have.

\subsubsection{Purity}

Understanding images may be a complex task because of the ambiguity and multiple perceptions of the same subject of analysis. In order to examine visuals through this frame, Machin (2010) suggests that "purity can mean simplicity and certainty, whereas hybridity can mean ambiguity and uncertainty, contamination and complexity" (p. 64). Examples of purity can be seen in arts and it reflects an ideology. In the case of the INAI, it is opted to show pictures by a short time, which are also easy to identify. Moreover, the video attempts to be simple and certain as a reinforcement to the aspects in regard to modulation. Under a more detailed analysis, it can be said that the use of such simplified pictures has the purpose of avoiding the audience spend so much time on what is depicted on the background. The INAI does not want people focus on complex pictures or background. Therefore, the representation of women in the spot (Image $1 \&$ 2), a person who seems to work in the countryside (Image 7), a person showing preoccupation about medicine are represented through simple pictures (Image 8). In the video, the INAI tries to illustrate the problems with simple images that do not require complex or critical thinking. 


\subsubsection{Modulation}

In order to analyze images, modulation takes a crucial part in the process. Following the use of this frame, according to Machin (2010) "this technique is typical of advertising and is used to connote cleanliness, simplicity, and certainty" (p. 66). Additionally, Machin and van Leeuwen (2007) mentioned that bringing morality and idealization of the pictures can be done through modulation. This frame function is described as "the scale that runs from a fully modulated color-for example, a blue that is richly textured with different tints and shades, as in paintings-to a flat color, as in comic strips or paintings" (p. 65). Regarding the INAI video, it can be claimed that it is attempt to be as clear, certain, and concise as possible. The use of flat colors recalls to simplicity and avoids the use of complex textures that may distract the audience form what the video tries to present. The modulation presented in the short clip also works as a comparison between what may be considered as 'good' and 'bad'. In this case they are represented with the high and low modulation in the pictures.

\subsubsection{Luminosity}

As the last part of the analysis, luminosity portrays a more unreal and fantastic perceptions of the images to explore. "Luminosity has a long history of being associated with the unworldly glow of magic and supernatural beings or objects" (Machin, 2010: 67). The use of this frame represents a more opened vision towards the analysis by prioritizing the luminous aspects of the video. The video plays with this aspect by using contrastive tones in during the questions and the answers, such as the cases of the aforementioned pictures. For example, when the questions are presented in the video, the use of luminosity decreases and gets low. The use of the pale palettes evokes negativity as mentioned in previously frames. On the opposite, at the time the questions are answered, the degree of luminosity increases and is used to reflect the positive aspects that the INAI wants to achieve. The role of luminosity presented in the video, follows the same patterns regarding 'good' against 'bad'. The latter is presented by the problems or doubts emerging from the current situation in the country while the former is reflected as possible solutions given by the INAI.

\section{Conclusion}

Throughout this paper, I have offered an analysis of the discourse of the INAI message broadcasted in diverse media. Machin's (2010) visual framework and Halliday's SFL (1978) were applied to scrutinize the main elements within the text and the images. The analysis of the first aspect indicates that the INAI suggest and promotes people's right to ask questions.in addition, this institution defends people and assumes that all their questions and answers will be answered or solved. However, there is no evidence enough that demonstrate that this happen. Supposedly, the INAI assumes that the questions "should" be replied. In real context, people needs to realize an extensive and hard paperwork only to find the answers. Regarding the visual frame, the images attempt to connect with the audience by including simple and familiar content on them. I consider the INAI when tries to catch the attention of the audience with the semiotics, it could be associated with the concepts the new government nowadays is implementing. In sum, the INAI presents an idealized message in its spot that questioning is something good and they will defend this practice. This message set the notion that they are against the frauds and corruption that Mexico has lived before. However, this idealistic message do not consider scenarios where the answers are pendent or simply unsolved and this is a reality that Mexico constantly faces. Therefore, even when this institution contributes to defending and encouraging people to ask, it should be provide clear guidance or demonstrate the results rather than work as an intermediate between the people and the rest of federal institutions. 


\section{Acknowledgements}

This research did not receive any specific grant from funding agencies in the public commercial, or not-for-profit sectors.

The author declares no competing interests.

\section{References}

Almurashi, W. A. (2016). An introduction to Halliday's systemic functional linguistics. Journal for the Study of English Linguistics, 4(1), 70-80. https://doi.org/10.5296/jsel.v4i1.9423

CONEVAL (2018). Diez años de medición de pobreza multidimensional en México: Avances y desafíos en política social, medición de la pobreza serie 2008-2018. https://www.coneval.org.mx/Medicion/MP/Documents/Pobreza 18/Pobreza 2018 CONEVAL.pdf.

De las Heras Demotecnia (2019). Traduciendo a México. http://www.demotecnia.com.mx/.

Fairclough, N., \& Wodak, R. (1977). Critical discourse analysis. In T van Dijk (Ed.), Discourse studies: A multidisciplinary introduction (pp. 258-284). SAGE.

Gage, J. (1993). Color and culture: Practice and meaning from antiquity to abstraction. Little Brown.

Garcia-Murillo, M. (2010). The effect of internet access on Government corruption. Social Science Research Network.

Halliday, M. A. K. (1978). Language as social semiotic: the social interpretation of language and meaning. University Park Press.

Halliday, M. A. K. (1985). An introduction to functional grammar. Arnold.

Halliday, M. A. K., \& Hasan, R. (1989). Language, context, and text: Aspects of language in a social semiotic perspective. Oxford University Press.

Haratyan, F. (2011). Halliday's SFL and social meaning. 2nd International Conference on Humanities, Historical and Social Sciences, 7(1), 260-264. http://www.ipedr.com/vol17/49-CHHSS\%202011H10074.pdf.

Hopf, A. C. (2016). Social media's impact on civic engagement in Mexico. [Master thesis, Naval Postgraduate School]. Institutional repository. https://core.ac.uk/download/pdf/45464837.pdf.

INAI (2017). Instituto Nacional de Transparencia, Acceso a la Información y Protección de Datos Personales. http://inicio.ifai.org.mx/SitePages/ifai.aspx.

INEGI (2015). Características educativas de la población. https://www.inegi.org.mx/temas/educacion/.

Itten, J. (1974). The art of color: The subjective experience and objective rationale of color. Van Nostrand Reinhold.

Mceneghan, J. S., \& Ragland, R. A. (2002). Municipal elections and community media. The Social Science Journal, 39(1), 207-208. https://doi.org/10.1016/s0362-3319(02)00163-5

Parkinson, J. (2002). Using the media in deliberative democracy. British Journal of Political Science, 36(1), 175-183. https://doi.org/10.1017/s0007123406000093

Kandinsky, W. (1977). Concerning spiritual in art. Dover Publications.

Lakoff, M., \& Johnson, M. (1980). Metaphors we live by. University of Chicago Press. 
Low, S. M., \& Lawrence-Zuñiga, D. (2003). The anthropology of space and place: Location and culture. Blackwell.

Machin, D., \& Van Leeuwen, T. (2007). Global media discourse. Routledge.

Machin, D. (2010). Analyzing popular music: Image, sound, text. SAGE.

Machinelly, D. (2011). ¿Qué es el IFAI? https://rendiciondecuentas.org.mx/que-es-el-ifai/.

Otero, G. (2018). Morena y la cuarta transformación histórica de México. Observatorio del desarrollo. Investigación, reflexión y análisis, 7(21), 37-43. https://agua.org.mx/wpcontent/uploads/2019/05/Observatorio-del-Desarrollo-no.-21.pdf.

Ramírez, D. (2015). Fighting corruption in Mexico: Social media and its impact in public accountability. Iberoamérica Social: Revista Red de Estudios Sociales, 5(1), 36-45. http://iberoamericasocial.com/fighting-corruptionin-mexico-social-media-and-its-impact-inpublic-accountability-combatiendo-la-corrupcion-en-mexico-las-redes-sociales-y-su-impacto-enla-rendicion-de-cuentas/.

Secretaria de Función Pública (2020). Instituto Nacional de Transparencia, Acceso a la Información y Protección de Datos Personales (INAI). https://www.gob.mx/sfp/documentos/instituto-nacionalde-transparencia-acceso-a-la-informacion-y-proteccion-de-datos-personales-inai.

Torcal, M. (2003). Political disaffection and democratization history in new democracies. In M. Torcal \& J. R. Montero (Eds.), Political disaffection in contemporary democracies: Social capital, institutions and politics (pp. 157-189). Routledge.

van Dijk, T. A. (1992). Discourse and the denial of racism. Discourse and Society 3(1), 87-118. https://doi.org/10.1007/978-1-137-07299-3 6

van Dijk, T. A. (1993). Elite discourse and racism. SAGE.

Wang, J. (2010). A critical discourse analysis of Barack Obama's speeches. Journal of Language Teaching and Research, 1(2), 254-261. https://doi.org/10.4304/jltr.1.3.254.-261

We Are Social Singapore (2016). Time Spent on the Internet.

http://www.slideshare.net/wearesocialsg/digital-in2016/25wearesocialsg 25TIME_SPENT ON THE.

Whitehead, N. L., \& Wright, R. (2004). In darkness and secrecy. Duke University Press.

Wodak, P. R., \& Meyer, M. (2008). Methods of critical discourse analysis. SAGE.

Wodak, R. (2001). What CDA is about: A summary of its history, important concepts and its developments. In: R. Wodak \& M. Meyer (Eds.), Methods of critical discourse analysis (pp. 1-13). SAGE. 
G. S. Rodas Hernández - Analyzing the Visuals and the Message Sent in the INAI Spot in Mexico

C O A $\mathrm{s}$ 